\title{
Risk of hospitalization of elderly rural workers in the state of Rio Grande do Sul
}

Jorge Luiz de Andrade Trindadel (ID Alan Silva Schukes ${ }^{2}$ ID

Marielly de Moraes ${ }^{3}$ ID Alexandre Simões Dias ${ }^{1,4} \mathbb{D}$

\section{Abstract}

Objective: To analyze the risk of hospitalization of elderly rural workers in the state of Rio Grande do Sul, Brazil. Method: A cross-sectional, population-based study was carried out of retired rural workers $(\mathrm{N}=604)$, over 60 years of age, of both genders, selected by clusters. In order to evaluate the risk of hospitalization, the Probability of Repeated Hospitalization (or PIR) instrument validated and evaluated for Brazil was used. Risk of hospitalization was calculated through logistic regression analysis, and was classified into the following strata: low $(<0.300)$; medium (0.300-0.399); medium-high (0.400-0.499) and high ( $\geq 0.500)$. Results: The rural elderly persons surveyed had a low risk of hospitalization $(n=553 ; 91.6 \%)$. There was a predominance of men among the medium to high risk categories $(n=42 ; 82.3 \%$ ), distributed mainly in the Santa Maria, Sul and Camaquã regions. Conclusion: The results of the present study suggest a low risk of hospitalization among this population, however, there is a need for improved, more profound and robust research into the identification of factors associated with the health specificities of this population.

\footnotetext{
Universidade Federal do Rio Grande do Sul, Escola de Educação Física, Fisioterapia e Dança, Programa de Pós-graduação em Ciências do Movimento Humano. Porto Alegre, Rio Grande do Sul, Brasil.

2 Universidade Feevale, Instituto de Ciências da Saúde, Curso de Educação Física. Novo Hamburgo, Rio Grande do Sul, Brasil.

3 Universidade Feevale, Instituto de Ciências da Saúde, Curso de Fisioterapia. Novo Hamburgo, Rio Grande do Sul, Brasil.

4 Universidade Federal do Rio Grande do Sul, Faculdade de Medicina, Programa de Pós-graduação em Ciências Pneumológicas. Porto Alegre, Rio Grande do Sul.

Keywords: Hospitalization. Patient Readmission. Health of the Elderly. Rural Population. 


\section{INTRODUCTION}

The biological conditions inherent to the aging process make the elderly more susceptible to morbidities resulting from their physical state. They therefore use health services more frequent, suffer more hospitalizations and stay in hospital for longer than other age groups, making them more susceptible to complications unrelated to the main cause of hospitalization, such as the impairment of functionality ${ }^{1,2}$. In general, the diseases suffered by the elderly are chronic and multiple, persist for several years and require constant monitoring, permanent care, continuous medication and periodic examinations ${ }^{1-3}$.

When researching scientific production on the hospitalization of the elderly, Lima et al. ${ }^{4}$ emphasized that this reality represents a great challenge for public health management, due to its significant economic impact.

However, studies on the use of specialized services by the population aged over 60 years in Brazil rarely include data from the rural population ${ }^{5}$. Dal Pizzol et al. ${ }^{6}$ state that elderly people living in rural areas can exhibit a different pattern of the use of health services to the urban population, both qualitatively and quantitatively. The non-availability of health services close to the homes of the elderly, including basic health care units, or reduced access to these services when available in other places due to transportation difficulties, can be important factors in relation to the use of health services?.

The financial constraints and social isolation of rural dwellers can also contribute to reduced access to basic health services and, consequently, worsening health conditions, which can lead to increased consumption of specialized services, such as hospitalization.

For this reason, to improve system planning, it is necessary to develop mechanisms to identify the elderly subgroups that require specialized health services more urgently and more intensely, a characteristic described in literature in this field as the frailty syndrome ${ }^{8}$.
Thus, effective instruments for evaluating the risk of hospitalization of the elderly population, such as the Probability of Repeated Admission (PRA) scale, are an extremely useful tool, especially for the elaboration of strategies of health management policies $^{9,10}$.

A systematic review and meta-analysis in the UK by Wallace et al. ${ }^{11}$ confirmed the reliability of the PRA instrument as a predictor of future hospital admission (cluster specificity $=96 \%, 95 \%$ CI, 95.8$96.7=95 \%)$. Thus, participants stratified as high risk (score $\geq 0.5$ ) are highly likely to be admitted to hospital the following year, and this risk score is a reliable predictor of future hospital admission.

Brazilian experience of the use of PRA was described by Perez and Lourenço ${ }^{10}$ in a systematic review, reaffirming its applicability as a tool for tracking the risk of hospitalization. Oliveira ${ }^{12}$, also in a systematic review, identified the use of this instrument and its effectiveness, establishing it as an effective tool in the elaboration of preventive management strategies ${ }^{13-16}$.

The present study aimed to analyze the risk of hospital admission of elderly rural workers in the state of Rio Grande do Sul, Brazil.

\section{METHOD}

The present study comprises a cross-sectional, population-based study with sample selection carried out by clusters and systematized based on the identification of the regional units $(\mathrm{N}=24)$ of the Federation of Rural Workers of Rio Grande do Sul (or FETAG-RS) and the respective workers unions $(\mathrm{N}=348)$ distributed in the 497 municipal districts of the state.

The sample consisted of 604 people over 60 years of age, affiliated with the rural workers' union of the state and resident in 12 of the 24 regional and 28 municipal units, dispersed throughout the mesoregions of the state.

The 12 regional units were chosen in a random manner, and were: 1- Médio e Alto Uruguai ( $\mathrm{n}=154)$; 
2- Serra do Alto Taquari ( $\mathrm{n}=26)$; 3 - Litoral $(\mathrm{n}=53)$; 4- Sul ( $\mathrm{n}=30) ; 5$ - Fronteira ( $\mathrm{n}=20) ; 6$ - Missões II $(\mathrm{n}=50) ; 7$ - Santa Maria $(\mathrm{n}=45) ; 8$ - Vale do Rio Pardo e Baixo Jacuí ( $\mathrm{n}=33$ ); 9- Camaquã ( $\mathrm{n}=27$ ); 10- Passo Fundo ( $\mathrm{n}=73)$; 11- Vale do Rio dos Sinos e Serra $(n=43) ; 12$ - Santa Rosa $(n=50)$.

The sample size was established based on a $95 \%$ confidence level and a 5\% sampling error, a design effect of 1.5 and a correction for the finite population, with an initial calculated sample of 576 ( $384 \times 1.5=576)$. The calculation base considered a universe of 387,000 rural elderly people in 2013. The sample allocation was carried out in proportion to the number of elderly in each stratum, observed in the union branches of the regional units chosen in the investigation process.

Cognitive evaluation was used as a selection criterion, based on the Mini Mental State Exam (MMSE) with a cut-off of 18 points for the illiterate population and 23 points for individuals with more than one year of schooling ${ }^{17}$. Those with communication difficulties who lived in institutions for the elderly were excluded. Contact with the respondents was intermediated by the unions of the selected municipal districts and the interviews were carried out in homes or at events, in order to achieve saturation based on the number corresponding to each location chosen, on a random basis. The average duration of the interviews was 20 minutes. The researchers, who were university students and professionals, participated voluntarily and were properly trained before the information was collected. Data collection was performed in 2017 and 2018.

The instrument used in this study, known as the Probability of Repeated Admission (PRA) scale, was advocated by Boult et al. ${ }^{13}$ and is a simple screening tool for the risk of hospitalization in the elderly population.

Risk factors related to the PRA include age, gender, self-perception of health, history of hospital admission in the last year, number of medical visits, presence of diabetes, heart disease and caregiver availability.

In Brazil, the use of the PRA was attested to by Veras $^{14}$, Negri et al..$^{15}$ and validated by Dutra et al. ${ }^{16}$.
The risk of hospital admission was calculated by means of a logistic regression model, with the formula: $\mathrm{PRA}=\mathrm{eBX} /(1+\mathrm{eBX})$, where: $\mathrm{PIR}=$ probability of repeated admission; $\mathrm{E}=$ natural logarithm; $\mathrm{BX}=$ $\mathrm{B} 0+\mathrm{B} 1 \mathrm{X} 1+\mathrm{B} 2 \mathrm{X} 2+\ldots \mathrm{B} 13 \mathrm{X} 13 ; \mathrm{B} 0=$ constant of the logistic regression equation $(-1.802) ; \mathrm{X}=1$ or 0 , presence or absence of each risk factor; $\mathrm{B}=$ logistic regression coefficient for each risk factor ${ }^{14,18-20}$.

Risk factors related to the PRA variables, when applied to a logistic regression model, generate values from 0 to 1 , where higher values determine a higher risk of hospital admission. For the reference values, the studies of Pacala et al. ${ }^{18,19}$ were used. The degree of frailty was calculated by means of the logistic regression of each risk factor, according to Veras $^{14}$. In this study, the risk of hospital admission was calculated using logistic regression analysis and classified in the strata proposed by Veras ${ }^{14}$ as low (<0.300); medium (0.300-0.399), medium-high (0.400-0.499) and high ( $\geq 0.500)$ (Chart 1).

The research data was processed in a spreadsheet with double entry of data, validation and data conferencing. The data was subsequently transferred to the Statistical Package for the Social Science (SPSS) version 24.0, for statistical analyzes.

The data were analyzed using descriptive statistics and the relationships between the frailty phenotypes and the variables by means of frequency distribution and Person's Correlation test, considering values of $p \leq 0.05$ as significant.

The study complied with Resolution $\mathrm{N}^{\circ}$ 466/2012 and was approved by the Research Ethics Committee of the Universidade Federal do Rio Grande do Sul, under $n^{\circ} 1.716 .579$ on September 8, 2016. All the participants signed a Free and Informed Consent Form.

\section{RESULTS}

The sample studied $(\mathrm{N}=604)$ was composed of people aged between 60 and 93 years, with a mean age of $69.6( \pm 7.1)$ years. Men were the majority $(n=321)$ representing $53.1 \%$ of the study population, while women ( $n=283)$ accounted for $46.9 \%$. 
The mean PRA score was $0.15( \pm 0.08)$. In a general context, the prevalence of PRA in the group represented $15.1 \%(\mathrm{n}=91)$ of the overall population surveyed $(\mathrm{N}=604)$, presenting a low risk of hospital admission ( $\mathrm{n}=553,91.6 \%$ ), and there was a predominance of the male population in the Medium ( $\mathrm{n}=33 ; 80.5 \%)$; Medium-High ( $\mathrm{n}=7 ; 87.5 \%)$ and High $(\mathrm{n}=2 ; 100 \%)($ Chart 1).

Chart 1. Stratification of the probability of repeated admission (PRA) in the population of elderly retired rural workers. Rio Grande do Sul (N=604), 2017-2018.

\begin{tabular}{|l|l|l|}
\hline Stratification of Risk & Probability of Repeated Admission (PRA) & $\mathrm{n}(\%)$ \\
\hline High & $\geq 0.500$ & $2(0.3)$ \\
\hline Mean-High & From 0.400 to 0.499 & $8(1.3)$ \\
\hline Mean & From 0.300 to 0.399 & $41(6.8)$ \\
\hline Low & $<0.300$ & $553(91.6)$ \\
\hline Total & $604(100.0)$ \\
\hline
\end{tabular}

We observed that the rural elderly persons surveyed had a balanced perception between positive $(\mathrm{n}=312,51.6 \%)$ and negative $(\mathrm{n}=292 ; 47.4 \%)$ concepts of their health (Table 1), placing the group surveyed among the concepts of regular and $\operatorname{good}(\mathrm{n}=503$, $83.3 \%$ ). However, there was a predominance of the most negative (poor and fair) perceptions in the group with the highest hospital admission risk.

In general, the distribution of hospitalizations in the last 12 months, as a variable of the PRA, tended towards a reduction in stratified scores, that is, there was a greater number of people with few or no hospitalizations. However, the Medium and Medium-High risk factor strata values were higher in relation to individuals with more than one hospitalization (Table 1).

In relation to the number of doctor's appointments, it was observed that the majority of individuals had sought medical assistance in the previous year. However, individuals with a high and a medium-high risk of hospitalization reported having gone to the doctor or clinic more often ( $>3$ times). In terms of chronic diseases, a diagnosis of diabetes mellitus was reported by the Medium-High ( $\mathrm{n}=5,62.5 \%$ ) and High ( $\mathrm{n}=2 ; 100 \%$ ) groups. The Low and Medium risk groups, meanwhile, accounted for $80.7 \%(\mathrm{n}=446)$ and $58.5 \%(\mathrm{n}=24)$ of those who did not have the disease, respectively. Cardiovascular diseases were found to be more closely related to the at risk groups, with only the Low risk group containing a concentration of individuals without a diagnosis and/or symptoms of any cardiovascular disorder $(\mathrm{n}=435,78.7 \%)$.

Analyzing the variables based on gender, there was (table 2) a predominance of men in the highest risk stratification scores, with $13.1 \%(\mathrm{n}=42)$, in contrast to $3.2 \%(n=9)$ of women. In contrast, there is homogeneous distribution among the groups in relation to the perception of health, the presence of chronic diseases and perceptions of social support when referring to having a caregiver, where needed.

In terms of medical consultations, greater numbers of men reported not having sought any medical treatment in the previous year $(n=49,15 \%)$.

In relation to age, a significant trend in the distribution of risk scores was identified mainly in the 70-79 year-old group, when the sample was analyzed $(p=0.022)$.

Regarding the regions surveyed (Table 3), although the prevalence of the risk of hospital admission is low, there was a distribution of Medium to High PRA scores in the South (Camaquã and Pelotas) and Santa Maria regions. However, the identification 
of Medium, Medium-High and High risks can be seen, with distribution in the regions of Santa Maria and Camaquã. The Vale do Rio dos Sinos and Serra region $(n=43 ; 100 \%)$ contained only elderly persons from the Low risk group. Medium risk, meanwhile, has a slightly greater distribution in the regions of Pelotas (South) $(\mathrm{n}=7 ; 23.3 \%)$, Santa Maria $(\mathrm{n}=5 ; 11.1 \%)$ and Litoral (coast) $(n=5 ; 9.4 \%)$.

Table 1. Distribution of risk factors for hospital admission in the elderly rural population of Rio Grande do Sul $(\mathrm{N}=604), 2017$ and 2018.

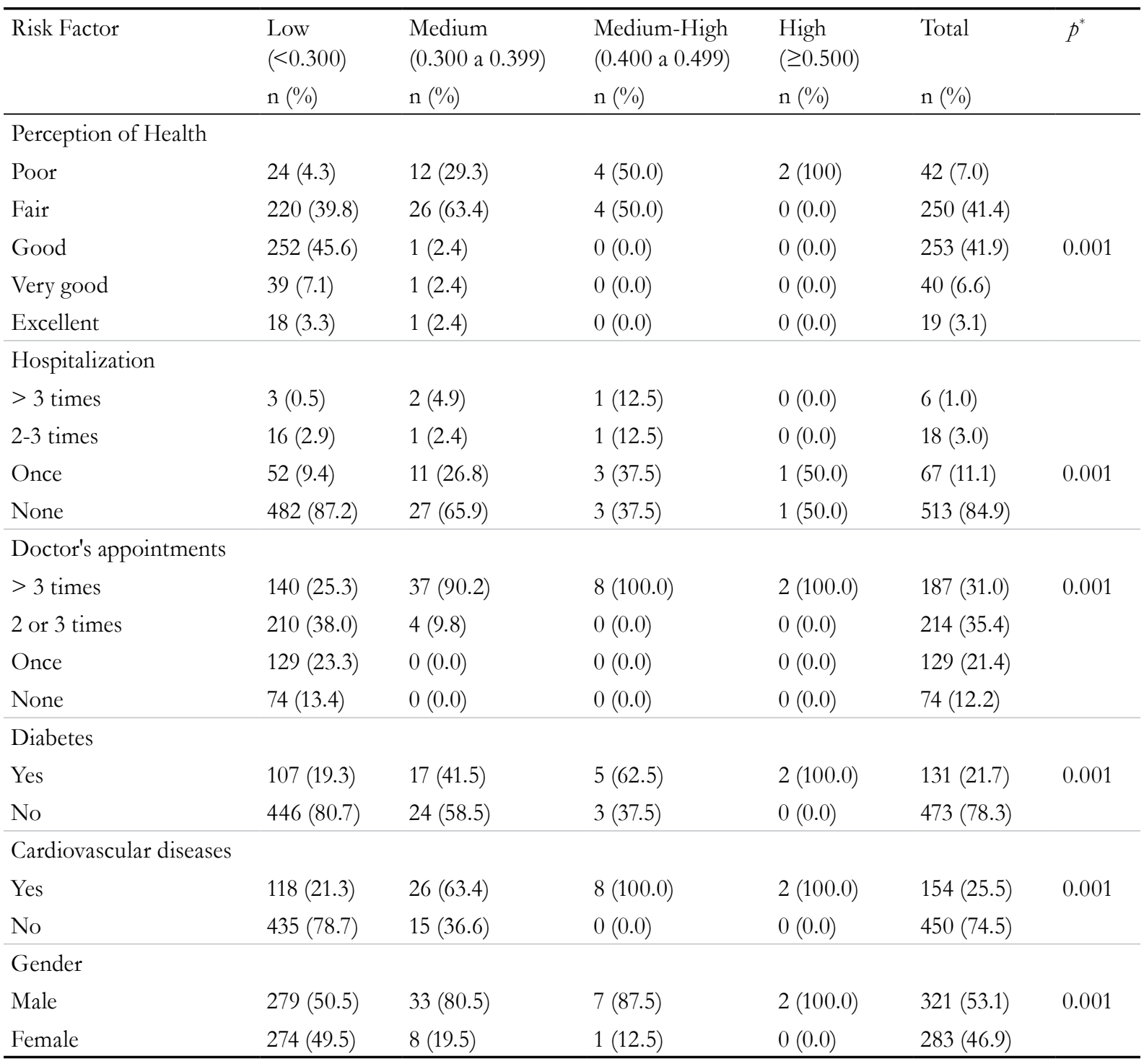

*Pearson's Chi-squared test. 
Table 2. Distribution of the elderly rural population of Rio Grande do Sul, in relation to hospital admission risk variables, by gender ( $\mathrm{N}=604), 2017$ and 2018.

\begin{tabular}{|c|c|c|c|c|}
\hline \multirow[t]{3}{*}{ Variables } & \multicolumn{2}{|c|}{ Gender } & \multirow{3}{*}{$\begin{array}{l}\text { Total } \\
\text { n }(\%)\end{array}$} & \multirow[t]{3}{*}{$p$} \\
\hline & Female & \multirow{2}{*}{$\begin{array}{l}\text { Male } \\
\mathrm{n}(\%)\end{array}$} & & \\
\hline & $\mathrm{n} \quad(\%)$ & & & \\
\hline \multicolumn{5}{|c|}{ Age Range (years) } \\
\hline $60-69$ & $154(54.4)$ & $169(52.6)$ & $323(53.4)$ & 0.022 \\
\hline $70-79$ & $99(35.0)$ & $113(35.2)$ & $212(35.2)$ & \\
\hline $80+$ & $30(10.6)$ & $39(12.1)$ & $69(11.4)$ & \\
\hline \multicolumn{5}{|c|}{ Health Perception } \\
\hline Excellent & $10(3.5)$ & $9(2.8)$ & $19(3.1)$ & \\
\hline Very good & $20(7.1)$ & $20(6.2)$ & $40(6.6)$ & \\
\hline Good & $119(42.0)$ & $134(41.7)$ & $253(41.9)$ & \\
\hline Fair & $111(39.2)$ & $139(43.3)$ & $250(41.4)$ & \\
\hline Poor & $23(8.1)$ & $19(5.9)$ & $42(7.0)$ & \\
\hline \multicolumn{5}{|c|}{ Medical appointment } \\
\hline None & $25(8.8)$ & $49(15.3)$ & $74(12.2)$ & \\
\hline Once & $63(22.3)$ & $66(20.6)$ & $129(21.4)$ & \\
\hline 2 or 3 times & $98(34.6)$ & $116(36.1)$ & $214(35.4)$ & \\
\hline$>3$ times & $97(34.3)$ & $90(28.0)$ & $187(31.0)$ & \\
\hline \multicolumn{5}{|c|}{ Diabetes Mellitus } \\
\hline No & $219(77.4)$ & $254(79.1)$ & $473(78.3)$ & \\
\hline Yes & $64(22.6)$ & $67(20.9)$ & $131(21.7)$ & \\
\hline \multicolumn{5}{|c|}{ Cardiovascular disease } \\
\hline No & $205(72.4)$ & $245(76.3)$ & $450(74.5)$ & \\
\hline Yes & $78(27.6)$ & $76(23.7)$ & $154(25.5)$ & \\
\hline \multicolumn{5}{|l|}{ Caregiver } \\
\hline Yes & $255(90.1)$ & $301(93.8)$ & $556(92.1)$ & \\
\hline No & $28(9.9)$ & $20(6.2)$ & $48(7.9)$ & \\
\hline \multicolumn{5}{|c|}{ Hospital admission } \\
\hline No & $244(86.2)$ & $269(83.8)$ & $513(84.9)$ & \\
\hline Yes & $39(13.8)$ & $52(16.2)$ & $91(15.1)$ & \\
\hline \multicolumn{5}{|c|}{ Probability of Repeated Admission } \\
\hline Low & $274(96.8)$ & $279(86.9)$ & $553(91.6)$ & \\
\hline Medium & $8(2.8)$ & $33(10.3)$ & $41(6.8)$ & 0.001 \\
\hline Medium-High & $1(0.4)$ & $7(2.2)$ & $8(1.3)$ & \\
\hline High & $0(0.0)$ & $2(0.6)$ & $2(0.3)$ & \\
\hline
\end{tabular}


Table 3. Distribution of Probability of Repeated Admission (PIA) in relation to the regions of residence of the elderly retired rural workers in the state of Rio Grande do Sul (N=604), 2017 and 2018.

\begin{tabular}{llllll}
\hline Regional branches* & $\begin{array}{l}\text { Low } \\
(<0.300)\end{array}$ & $\begin{array}{l}\text { Mean } \\
(0.300 \text { to } 0.399)\end{array}$ & $\begin{array}{l}\text { Mean-High } \\
(0.400 \text { to } 0.499)\end{array}$ & $\begin{array}{l}\text { High } \\
(\geq 0,500)\end{array}$ & Total \\
& $\mathrm{n}(\%)$ & $\mathrm{n}(\%)$ & $\mathrm{n}(\%)$ & $\mathrm{n}(\%)$ & $\mathrm{n}(\%)$ \\
\hline Médio e Alto Uruguai & $147(26.6)$ & $6(14.6)$ & $1(12.5)$ & $0(0.0)$ & $154(25.5)$ \\
Passo Fundo & $67(12.1)$ & $5(12.2)$ & $1(12.5)$ & $0(0.0)$ & $73(12.1)$ \\
Litoral (Coast) & $48(8.7)$ & $5(12.2)$ & $0(0.0)$ & $0(0.0)$ & $53(8.8)$ \\
Santa Rosa & $48(8.7)$ & $2(4.9)$ & $0(0.0)$ & $0(0.0)$ & $50(8.3)$ \\
Missões II & $47(8.5)$ & $3(7.3)$ & $0(0.0)$ & $0(0.0)$ & $50(8.3)$ \\
Santa Maria & $36(6.5)$ & $5(12.2)$ & $3(37.5)$ & $1(50.0)$ & $45(7.4)$ \\
Vale do Rio dos Sinos & $43(7.8)$ & $0(0.0)$ & $0(0.0)$ & $0(0.0)$ & $43(7.2)$ \\
e Serra & & & & $0(0.0)$ & $33(5.4)$ \\
Vale do Rio Pardo e & $31(5.6)$ & $2(4.9)$ & $0(0.0)$ & & 0.003 \\
Baixo Jacuí & & & $2(25.0)$ & $0(0.0)$ & $30(4.9)$ \\
Sul (Pelotas) & $21(3.8)$ & $7(17.1)$ & $1(12.5)$ & $1(50.0)$ & $27(4.5)$ \\
Camaquã & $23(4.2)$ & $2(4.9)$ & $0(0.0)$ & $0(0.0)$ & $26(4.3)$ \\
Serra do Alto Taquari & $24(4.3)$ & $2(4.9)$ & $0(0.0)$ & $0(0.0)$ & $20(3.3)$ \\
Fronteira & $18(3.3)$ & $2(4.9)$ & &
\end{tabular}

$*$ Chi-squared test $=60.142$; degree of freedom $=33 ; p$-value $=0.003$.

\section{DISCUSSION}

The profile of the risk of hospital admission of the researched population, analyzed according to the variables proposed by Boult et al. ${ }^{13}$, indicates certain peculiarities.

The rural elderly persons in this study exhibited a low risk of hospital admission; unlike the studies by Negri et al. ${ }^{15}$ which identified a higher risk in the rural elderly population $(54.6 \%)$ than in the urban elderly population (42.4\%).

In general, other studies that evaluated urban or urban and rural samples, such as Estrella et al. ${ }^{21}$, Veras ${ }^{14}$ and Dutra et al. ${ }^{16}$ found a higher prevalence of low risk in the population $(76.3 \%, 75.0 \%$ and $64.3 \%$, respectively). Low risk was more prevalent in these studies, with the progressive reduction of the other strata ${ }^{14,16,20,21}$.

The rural elderly in Rio Grande do Sul surveyed had a young profile, with a mean age of $69.6(+7.1)$ years. For Papalia et al. ${ }^{22}$ the term young elderly person normally refers to people aged 65 to 74 years who, according to the authors, are usually active, full of life and vigorous. Older people aged 75-84 years and those aged 85 or older are more prone to weakness and illness and may find it difficult to perform some activities of daily living ${ }^{22}$. While the authors base their work on American studies, which consider elderly persons as those older than 65 , it can still be inferred that the population studied has a significant prevalence of individuals at the beginning of the senility process and, therefore, better health conditions among the elderly.

A total of $53.4 \%$ of the studied group were concentrated in the 60 to 69 years age group $(\mathrm{n}=287)$ and $46.6 \%(\mathrm{n}=281)$ in the over 70 years of age range. We identified a direct relationship with age in the risk strata observed in this study, as in the studies described by Boult et al. ${ }^{13}$, which describe relationships of risk with more advanced ages. A study carried out in eight American states with elderly people hospitalized for acute strokes identified that $16.6 \%$ of this population was readmitted to hospital within 30 days and that the advancement of age was a predictive factor ${ }^{23}$. 
In terms of perception of health, it was observed that negative concepts were more closely related to a greater risk of hospitalization, however the population studied contains a higher prevalence of elderly people who described their health as good or regular. These findings are similar to those reported in other studies such as those of Dos Santos et al. ${ }^{20}$ and Garbaccio et al. ${ }^{24}$. However, differences with findings in literature were found in relation to negative health perception, as women were more likely to refer to their health as poor ${ }^{24}$. In this regard, Confortin et al. ${ }^{25}$ draw attention to the subjective judgment of the elderly in relation to their physical functioning, and health is included in this overall evaluation of the status described.

Hospital admissions were observed in 15.1\% ( $n=91$ ) of the group, with a higher percentage of cases in the Medium and Medium-High groups. Hospital readmission situations have been described in nonBrazilian studies, especially in relation to the presence of chronic diseases such as cardiovascular diseases ${ }^{26}$ or diabetes mellitus (DM). Ostling et al. ${ }^{27}$, indicate 30-day readmission rates for patients hospitalized with DM well above (14.4-22.7\%) the rate for all hospitalized patients $(8.5-13.5 \%)$.

Risk factors related to chronic diseases are consistently high, among readmission rates; especially those for heart failure, determining the need for strategies to systematically resolve this problem. Databased care models that incorporate risk predictions can be used at the point of care to optimize interventions and provide patient-centered care ${ }^{28}$.

In terms of regional aspects, differences were observed in the identification of greater risks of hospitalization in some regions, such as Santa Maria, Camaquã and the Southern region, as previously mentioned. A more sensitive analysis of factors associated with these findings requires a careful, deeper investigation, especially considering the prevalence of elderly persons at medium and high risk identified in this study.

Overall, it was found that $91.6 \%$ of the population studied had a low risk of hospitalization. In Brazilian studies, a low risk trend was also identified, as in the work by Veras ${ }^{14}$, where the studied population presented a rate of $75.8 \%$. It could be said that these $8.4 \%$ of the studied population at greater risk is comparable to the approximately $7 \%$ described by the aforementioned Brazilian and American studies $^{14,16,20,21,26}$.

As a limitation of this study it is worth noting its cross-sectional nature, and that it reflects the condition of rural workers residing in a certain region of the country, who are unionized and the majority of whom are active in their labor and social practices. The associations measured, in the same way, reflect the low number of subjects identified as having a significant risk of hospital admission.

Perez ${ }^{8}$ points out that, although there is evidence of the usefulness of the PRA for Brazil, it was created from the identification of predictive variables based on empirical data from North American samples; indicating a need for the evaluation for distinct socioeconomic and cultural realities before its systematic use. In this sense, the present study reflects conditions of reality in the use of the factors of the PRA, without ruling out other conditions that may have an influence on the outcome of hospital admission and indicating the need for robust studies on the subject with this population. Another pertinent issue is the scarcity of literature concerning investigations in Brazil, which would allow comparison with the present study.

\section{CONCLUSION}

Population aging is a reality in Brazil, bringing with it socio-political demands inherent to this phase of the life cycle. Among these, those related to the characteristics of the use of health services by the elderly, especially hospitals, are worthy of note.

It can be concluded that the risks of hospital admission of the studied group are associated with elderly men living in the south and center-west regions of Brazil, with the region of the center of the state or the Santa Maria and Camaquã regions, located in the metropolitan mesoregion, representing a reference point. Aspects related to the regional characteristics of the findings of this research suggest 
the need for more in-depth studies on several factors related to the Probability of Repeated Admission, especially those that may be associated with the rural elderly population.

Thus, the accelerated process of aging of the Brazilian population presupposes the necessity of understanding the specificities of this group, in relation to the management of health care resources, among other aspects relevant to a dignified and adequate quality of life for the elderly. Thus, the present study indicates certain peculiarities in relation to the demands of elderly persons retired from agricultural labor.

The perception of health and the elements of frailty of agricultural workers, as well as the conditions of access to health services, raise pertinent questions in relation to the agenda to be followed by healthcare managers. In this sense, the creation of suitable policies to address the protection and improvement of the quality of life of the aging population involves not only issues related to the consumption of health services, but also other elements that involve sectors responsible for access to services which are essential for the condition of preventing the frailty of the elderly.

\section{ACKNOWLEDGEMENTS}

The authors would like to thank the Federation of Rural Workers of Rio Grande do Sul (or FETAG-RS), the Regional Coordinators and the Unions of Rural Workers for their help in carrying out this study. We would also like to thank the retired agricultural workers of Rio Grande do Sul and all those who made this research viable.

\section{REFERENCES}

1. de Souza DGR, Doná F, da Nóbrega DV, dos Reis MDA, Lemos NDFD, Gazzola JM. Análise da funcionalidade de idosos hospitalizados em uma enfermaria de Clínica Médica. Rev Kairós. 2018:21(2):73-89.

2. Lamper MA, Barbosa CD, Coelho FL, Santos I. Uso de preditores de risco em idosos no Brasil: uma revisão integrativa. Rev Kairós. 2016;19(3):169-85.

3. Abreu DRDOM, Novaes ES, Oliveira RRD, Mathias TADF, MarconSS. Internação e mortalidade por quedas em idosos no Brasil: análise de tendência. Ciênc Saúde Colet. 2018:23(4):1131-41.

4. Lima AP, Mantovani MF, Ulbrich EM, Zavadil ETC. Produção científica sobre a hospitalização de idosos: uma pesquisa bibliográfica. Cogitare Enferm. 2009;14(4):740-7.

5. De Mera CMP, Netto CGA. Envelhecimento dos produtores no meio rural na região do Alto Jacuí/ RS e consequente migração para cidade. Estud Interdiscip Envelhec. 2014;19(3):759-74.

6. dal Pizzol TDS, Pons EDS, Hugo FN, Bozzetti MC, Sousa MDLRD, HilgertJB. Uso de medicamentos entre idosos residentes em áreas urbanas e rurais de município no Sul do Brasil: um estudo de base populacional. Cad Saúde Pública. 2012;28(1):104-14.
7. de Macedo E, Ulrich V, Bós AMG, Bós AJG. Fatores relacionados à autopercepção do estado de saúde em idosos residentes no meio rural do Brasil. Sci Med. 2018;28(3):1-9.

8. Perez M. Rastreamento de risco de desfechos desfavoráveis em idosos: o instrumento Probabilidade de internações repetidas. Rev HUPE. 2017;16(2):110-6.

9. O’Caoimh R, Cornally N, Weathers E, O'Sullivan $R$, Fitzgerald C, Orfila F, et al. Risk prediction in the community: a systematic review of case-finding instruments that predict adverse healthcare outcomes in community-dwelling older adults. Maturitas. 2015;82(1):3-21.

10. Perez M, Lourenco RA. Rede FIBRA-RJ: fragilidade e risco de hospitalização em idosos da cidade do Rio de Janeiro, Brasil. Cad Saúde Pública. 2013;29(7):1381-91.

11. Wallace E, Hinchey T, Dimitrov BD, Bennett K, Fahey T, Smith SMA. Systematic review of the probability of repeated admission score in community-dwelling adults. J Am Geriatr Soc. 2013;61(3):357-64.

12. Oliveira ECT. Detecção de risco para (re) hospitalização em idosos: uma revisão sistematizada. Rev Saúde Com. 2014;10(2):209-20. 
13. Boult C, Dowd B, McCaffrey D, Boult L, Hernandez R, Krulewitch H. Screening elders for risk of hospital admission. J Am Geriatr Soc. 1993;41(8):811-7.

14. Veras R. Em busca de uma assistência adequada à saúde do idoso: revisão da literatura e aplicação de um instrumento de detecção precoce e de previsibilidade de agravos. Cad Saúde Pública. 2003;19(3):705-15.

15. Negri LSA, Ruy GF, Collodetti JB, Pinto LF, Soranz DR. Aplicação de um instrumento para detecção precoce e previsibilidade de agravos na população idosa. Ciênc Saúde Colet. 2004;9(4):1033-46.

16. Dutra MM, Moriguchi EH, Lampert MA, Figueiredo CEP. Validade preditiva de instrumento para identificação de idosos com risco de hospitalização. Rev Saúde Pública. 2011;45(1):106-12.

17. Lourenço RA, Veras RP. Mini-Exame do Estado Mental: características psicométricas em idosos ambulatoriais. Rev Saúde Pública. 2006;(4):712-9

18. Pacala JT, Boult C, Boult L. Predictive validity of a questionnaire that identifies older persons at risk for hospital admission. J Am Geriatr Soc. 1995;43(4):374-7.

19. Pacala JT, Boult C, Reed RL, Aliberti E. Predictive validity of the PRA instrument among older recipients of managed care. J Am Geriatr Soc. 1997;45(5):614-7.

20. dos Santos FC, da Rosa PV, da Rosa LHT, Pribbernow SCM. Avaliação do risco de internação hospitalar de idosos da comunidade no município de Porto Alegre. Estud Interdiscip Envelhec. 2014;19(3):839-52.
21. Estrella K, Oliveira CEF, Sant'Anna AA, Caldas CP. Detecção do risco para internação hospitalar em população idosa: um estudo a partir da porta de entrada no sistema de saúde suplementar. Cad Saúde Pública. 2009;25(3):507-12.

22. Papalia DE, Olds SW, Feldman RD. Desenvolvimento humano. Porto Alegre: Artmed; 2006.

23. Hirayama A, Goto T, Faridi MK, Camargo Jr CA, Hasegawa K. Age-related difference in the rate and diagnosis of 30-day readmission after hospitalization for acute ischemic stroke. Int J Stroke. 2018;13(7):1-8.

24. Garbaccio JL, Tonaco LAB, Estevao WG, Barcelos BJ. Aging and quality of life of elderly people in rural areas. Rev Bras Enferm. 2018;71(Suppl 2):724-32

25. Cofortin SC, Giehl MWC, Schneider IJC, Orsi E. Autopercepção positiva de saúde em idoso: estudo populacional no sul do Brasil. Cad Saúde Pública. 2015;31(5):1049-60.

26. Al-Omary M, Davies A, Boyle A. Mortality and readmission following hospitalisation for heart failure in Australia: a systematic review and meta-analysis. Heart Lung Circ. 2017;26:139-40.

27. Ostling S, Wyckoff J, Ciarkowski SL, Pai CW, Choe $\mathrm{HM}$, Bahl V, et al. The relationship between diabetes mellitus and 30-day readmission rates. Clin Diabetes Endocrinol. 2017;3:2-8.

28. Mahajan SM, Heidenreich P, AbbottB, Newton A, Ward D. Predictive models for identifying risk of readmission after index hospitalization for heart failure: A systematic review. Eur J Cardiovasc Nurs. 2018;17(8):675-89. 